\title{
CONHECIMENTOS E CRENÇAS DE PROFESSORES SOBRE A EDUCAÇÃO INCLUSIVA: REVISÃO SISTEMÁTICA DA LITERATURA NACIONAL
}

\author{
GABRIELA DAL FORNO MARTINS ${ }^{1}$ \\ ORCID: https://orcid.org/0000-0001-6278-7302 \\ GABRIELA VIEIRA SOARES DE ABREU ${ }^{2}$ \\ ORCID: https://orcid.org/0000-0002-0750-3423 \\ MARLENE ROZEK ${ }^{3}$ \\ ORCID: https://orcid.org/0000-0001-8740-6166
}

\begin{abstract}
RESUMO: O presente estudo teve como objetivo mapear, de forma sistemática, a literatura científica brasileira sobre o tema dos conhecimentos e crenças de professores em relação à Educação Inclusiva. Para localizar os artigos, três bases de dados foram consultadas: Biblioteca Virtual em Saúde - Psicologia (BVS-PSI), Portal de periódicos da CAPES e Scielo. Os artigos identificados foram classificados de acordo com: ano e periódico; instituição e formação do primeiro autor; natureza da autoria; metodologia; técnicas de coleta; e temas de investigação. Após, analisou-se qualitativamente os resultados dos artigos que de forma mais específica investigaram conhecimentos e crenças. Os resultados indicaram que os estudos são recentes e têm aumentado nos últimos anos. A Educação Especial destacou-se como área que vem realizando essas discussões, sugerindo que a Educação Inclusiva vem sendo de maneira gradual incorporada como campo de discussão de outras áreas da Educação e de áreas afins. Esforços adicionais são necessários para que a Educação Inclusiva seja compreendida em seu caráter educacional, como uma nova forma de conceber os sujeitos e os processos de ensinar e aprender.
\end{abstract}

Palavras-chave: Formação de professores, Educação Inclusiva, Crenças, Conhecimentos.

\section{TEACHERS' KNOWLEDGE AND BELIEFS ABOUT INCLUSIVE EDUCATION: A SYSTEMATIC REVIEW OF THE NATIONAL LITERATURE}

\begin{abstract}
The present study aimed to systematically map the Brazilian scientific literature about what teachers know and believe regarding Inclusive Education. Thus, three databases were consulted: Biblioteca Virtual em Saúde - Psicologia (BVS-PSI), Portal de periódicos da CAPES and Scielo. The identified articles were classified according to: year and journal; institution and education of the first author; nature of authorship; methodology; collection techniques; and research topics. After, the findings reported in the articles that specifically investigated knowledge and beliefs were qualitatively analyzed. The analysis shows the studies are recent and interest in the topic is growing. Special Education stood out as the area driving the debates,

\footnotetext{
${ }^{1}$ Pontifícia Universidade Católica do Rio Grande do Sul (PUCRS), Porto Alegre, RS, Brasil. <gabriela.martins@pucrs.br>

2 Pontifícia Universidade Católica do Rio Grande do Sul (PUCRS), Porto Alegre, RS, Brasil. <soares.gabrielavieira@gmail.com>

${ }^{3}$ Pontifícia Universidade Católica do Rio Grande do Sul (PUCRS), Porto Alegre, RS, Brasil. < marlene.rozek@pucrs.br> Educação em Revista|Belo Horizonte|v.36|e218615|2020
} 
suggesting that Inclusive Education has been gradually incorporated as a field of discussion within other Educational areas and related fields. Additional efforts are required to ensure the educational character of Inclusive Education is fully understood as a new way of conceiving subjects and the processes of teaching and learning.

Keywords: Teacher education, Inclusive Education, Beliefs, Knowledge.

\section{CONOCIMIENTOS Y CREENCIAS DE LOS PROFESORES SOBRE LA EDUCACIÓN INCLUSIVA: UNA REVISIÓN SISTEMÁTICA DE LA LITERATURA NACIONAL}

RESUMEN: El presente estudio tuvo como objetivo mapear sistemáticamente la literatura científica brasileña sobre el tema de los conocimientos y las creencias de los docentes con relación a la educación inclusiva. Para localizar los artículos, se consultaron tres bases de datos: Biblioteca Virtual en Salud Psicología (BVS-PSI), Portal de revistas CAPES y Scielo. Los artículos identificados se clasificaron según: año y periódico; institución y formación del primer autor; naturaleza de la autoría; metodología; técnicas de recolección; y temas de investigación. Posteriormente, los resultados de los artículos que investigaron más específicamente el conocimiento y las creencias fueron analizados cualitativamente. Los resultados indicaron que los estudios son recientes y han aumentado en los últimos años. La Educación Especial se destacó como un área que ha estado llevando a cabo estas discusiones, lo que sugiere que la Educación Inclusiva se ha incorporado gradualmente como un campo de discusión en otras áreas de la Educación y áreas relacionadas. Se requieren esfuerzos adicionales para que la Educación Inclusiva se entienda en su carácter educativo, como una nueva forma de concebir las sujetos y los procesos de enseñanza y aprendizaje.

Palabras clave: Formación de profesores, Educación Inclusiva, Creencias, Conocimientos. 


\title{
INTRODUÇÃO
}

A história da Educação Inclusiva no Brasil e no mundo é bastante recente, de modo que ainda não estão plenamente consolidados os princípios e as ações que norteiam a atuação dos professores no cotidiano das escolas regulares. No país, isso pode ser explicado, em parte, pelas recentes mudanças, ocorridas desde o final do século XX, nas políticas de Educação Especial, as quais culminaram na publicação da Política Nacional de Educação Especial na Perspectiva da Educação Inclusiva (BRASIL, 2008).

Esta política consolidou, pelo menos em termos legais, a adoção da Educação Inclusiva enquanto perspectiva que deve orientar a atuação da Educação Especial no país. Logo no início do documento, afirma-se que:

\begin{abstract}
O movimento mundial pela educação inclusiva é uma ação política, cultural, social e pedagógica, desencadeada em defesa do direito de todos os estudantes de estarem juntos, aprendendo e participando, sem nenhum tipo de discriminação. A educação inclusiva constitui um paradigma educacional fundamentado na concepção de direitos humanos, que conjuga igualdade e diferença como valores indissociáveis, e que avança em relação à ideia de equidade formal ao contextualizar as circunstâncias históricas da produção da exclusão dentro e fora da escola (BRASIL, 2008).
\end{abstract}

Verifica-se que, nessa definição, estão implicados, sobretudo, aspectos éticos relacionados ao compromisso de garantir uma educação, de fato, para todos. Nesse sentido, o binômio inclusão-exclusão é central para que se compreenda que o movimento pela Educação Inclusiva se situa política e historicamente e busca enfrentar uma dívida persistente para com diferentes populações que vêm sendo excluídas da sociedade e da escola (DIAS, 2006; PATTO, 2008). Patto (2008) nos alerta, no entanto, que, embora o discurso da inclusão esteja bastante disseminado em diversas esferas de nossa sociedade, realizar uma "inclusão marginal" (p. 32), ou seja, formas pobres e insuficientes de inclusão, não resolverá o problema da exclusão.

Nessa direção, do ponto de vista do processo de escolarização, entende-se que o direito à educação não se restringe ao direito de acessar a escola, mas inclui o direito de aprender com qualidade, daí que a Educação Inclusiva também pressupõe compromissos pedagógicos (MARQUES, 2006). Aprender com qualidade pode significar muitas coisas, mas aqui assume-se que aprender vincula-se ao um processo de humanização e, portanto, de emancipação, que se contrapõe a uma compreensão tecnicista ou instrumental de educação (PATTO, 2008).

Qual o impacto da adoção do paradigma da Educação Inclusiva para a Educação Especial, a partir da política de 2008? Verifica-se que esta política reforça a Educação Especial como uma modalidade de educação escolar transversal a todos os níveis da Educação Básica, desde a Educação Infantil à Educação Superior (LDBEN, 1996), ou seja, a Educação Especial não é um sistema paralelo e tem como lócus de atuação a escola regular. Além disso, uma mudança importante que tal política estabeleceu foi em relação ao público-alvo da Educação Especial, passando-se de um público mais amplo, o dos alunos com "necessidades educacionais especiais" (NEE), tal como propunha a Resolução no 2/2001 (BRASIL, 2001), para um público mais específico: os alunos com deficiência(s) e com transtornos globais do desenvolvimento ${ }^{4}$ e altas habilidades/superdotação (BRASIL, 2008).

Portanto, a política direciona para a inclusão escolar, ou seja, a garantia de que esses sujeitos possam frequentar a escola regular (BUENO, 2008; MENDES, 2018). Já a atuação junto a esse público, segundo a política, deve ser realizada através do que se denominou "atendimento educacional especializado" (AEE), o qual "disponibiliza os recursos e serviços e orienta quanto a sua utilização no processo de ensino e aprendizagem nas turmas comuns do ensino regular” (BRASIL, 2008, p. 10).

Para Garcia (2013), ainda que a política de 2008 tenha garantido o direito desse público à escolarização, todas essas mudanças levaram a uma "superespecialização" da Educação Especial, que se

\footnotetext{
${ }^{4}$ Optou-se por manter o termo utilizado na Política Nacional de Educação Especial na Perspectiva da Educação Inclusiva (BRASIL, 2008), a saber, Transtorno Global do Desenvolvimento, mesmo que, a partir de 2013, com a publicação do Manual de Diagnóstico e Estatística dos Transtornos Mentais (DSM-5), tenha-se alterado essa nomenclatura para Transtorno do Espectro Autista".
} 
tornou muito mais responsável pela gestão de recursos e menos focalizada no processo pedagógico implicado no desenvolvimento escolar dos alunos. Esse trabalho de gestão de recursos associa-se prioritariamente ao que é feito na Sala de Recursos Multifuncionais, de modo que, para a autora, o trabalho "se mantém paralelo ao trabalho realizado na classe comum, o qual pouco incide sobre o processo de escolarização dos sujeitos da modalidade educação especial" (GARCIA, 2013, p. 109).

Assim, pode-se pensar que, mesmo a Educação Especial atuando dentro da escola regular, parece manter um trabalho paralelo e pouco focado no sentido ético e político da Educação Inclusiva. É nessa direção que Bueno (2008) esclarece que a inclusão escolar e a Educação Inclusiva são conceitos diferentes, uma vez que o primeiro implica uma "proposição política em ação, de incorporação de alunos que tradicionalmente têm sido excluídos da escola" (p.49), enquanto que a Educação Inclusiva "referese a um objetivo político a ser alcançado" (p.49).

Diante desse cenário complexo e em movimento, indaga-se a respeito do papel e da formação dos profissionais não somente da Educação Especial, mas também dos professores que atuam nas classes regulares, aspecto pouco mencionado na política de 2008. Afora a informação de que devem atuar em colaboração com os profissionais do AEE, não há qualquer orientação em relação ao que se espera desse profissional, tampouco a respeito de sua formação.

Nesse sentido, interessou-nos poder refletir sobre o que os professores que atuam nas classes regulares conhecem e pensam a respeito dos processos inclusivos que ocorrem no cotidiano escolar, bem como sobre a própria política de Educação Inclusiva. Assim, o presente estudo teve como objetivo mapear, de forma sistemática, a literatura científica brasileira sobre o tema dos conhecimentos e crenças dos professores em relação à Educação Inclusiva.

A escolha por uma revisão sistemática da literatura justificou-se a partir de seu potencial em desvelar os caminhos já percorridos nesse campo e as perspectivas futuras de investigação e ação. Interessava-nos, também, descobrir a partir de que perspectivas e de que lugares essas discussões vinham sendo feitas na academia.

Entendemos que o debate sobre os conhecimentos e as crenças de professores não pode ser descolado do tema mais geral da formação docente. Trata-se de uma questão central para a área da Educação em geral e para a Educação Inclusiva, em particular, já que a essência do processo educacional está no ensinar e no aprender, que ocorrem na relação entre seres humanos, uma relação de eticidade (ROZEK, 2010). Dessa forma, é por "exigência ética que a formação do professor deve se conceber e se realizar; o investimento na formação e na atuação profissional não pode se reduzir a uma qualificação técnica e metodológica" (ROZEK, 2010, p. 148).

Dessa forma, neste estudo, utilizou-se o termo "crenças" para designar todas as ideias que permeiam a formação do professor e que não dizem respeito aos conhecimentos técnico e instrumental. Tomou-se o conceito utilizado por Ferreira (2007), após ter realizado ampla revisão crítica sobre distintas definições presentes na literatura:

Olhando estes enunciados, poderemos dizer, num registro próximo do de Anderson e Bird (1995), que as crenças do professor dizem respeito ao conjunto de premissas ou de proposições não testadas a partir das quais se organiza uma parte importante dos quadros de referência ou das perspectivas que os docentes utilizam para dar sentido às suas práticas. (FERREIRA, 2007, p. 100).

Considerando essa definição, entendemos que a formação deve permitir que, para além dos conhecimentos técnicos, o professor possa construir novos significados e sentidos sobre o seu trabalho, definindo o que se quer e o que não se quer, e o que se pode como docente. Foi essa concepção que permeou a estruturação metodológica do estudo, bem como as discussões feitas a partir dos achados da revisão de literatura.

\section{MÉTODO}

Realizou-se uma revisão sistemática da literatura, a qual consiste em buscar, de modo organizado, o maior número de publicações possíveis sobre o tema pretendido (COSTA; ZOLTOWSKI, 2014). Foram considerados apenas artigos publicados nacionalmente e, para atingir o maior número de 
trabalhos, três bases de dados foram consultadas: Biblioteca Virtual em Saúde - Psicologia (BVS-PSI), Portal de Periódicos da CAPES e Scielo. Não foi limitado um período inicial para a busca, sendo a data final janeiro de 2016, quando as bases foram consultadas.

Quanto às palavras-chave a serem utilizadas nas buscas, embora o foco principal fossem os estudos sobre conhecimentos e crenças em relação à Educação Inclusiva, optou-se por incluir também palavras mais gerais ligadas ao campo da formação de professores. Essa decisão foi tomada de modo a viabilizar que um número maior de estudos fosse identificado, considerando que nem sempre aqueles que investigam conhecimentos e crenças fazem uso exato dessas palavras. Da mesma forma, essa definição vincula-se ao pressuposto de que os conhecimentos e as crenças são partes importantes do processo mais geral de formação de professores.

Assim, no que diz respeito ao tema "formação", foram utilizadas as expressões: "formação de professores"; "formação docente"; "concepções de professores"; "conhecimentos de professores"; e "crenças de professores". Quanto ao tema "Educação Inclusiva", além do próprio termo, foram utilizadas as expressões: "Educação Especial"; "deficiência"; "inclusão escolar"; "necessidades educativas especiais"; "pessoa com necessidades educativas especiais". Todas essas expressões foram combinadas entre si, aos pares (p. ex., "formação de professores" AND "Educação Inclusiva"; "formação de professores" AND "deficiência", entre outros).

\section{Procedimentos de análise de dados}

O corpus de análise inicial foi constituído por 969 resumos. Destes, 164 foram encontrados na base Scielo, 463 na base BVS-PSI e 342 no Portal de Periódicos da CAPES. Todos foram lidos, de modo que, primeiramente, foram exclúdos 408 artigos repetidos. Em uma segunda etapa, foram identificados os artigos que não se enquadravam no tema do presente estudo, os quais abordavam a deficiência com outro sentido (p. ex., deficiência imunológica e de nutrientes). Também foram excluídos artigos sobre a deficiência no trabalho e na família, sem enfocar o ambiente escolar. Ao total, excluíramse mais 393 resumos.

Por sua vez, na terceira etapa da análise, mais refinada, dois pesquisadores trabalharam conjuntamente e um terceiro foi acionado em momentos de discordância. Nessa etapa, excluíam-se mais 67 artigos que estavam relacionados com a formação de professores, mas que não estavam associados com a Educação Inclusiva, e vice-versa.

Restaram 101 artigos, que foram lidos na íntegra e submetidos a uma Análise de Conteúdo (BARDIN, 2010). As publicações foram classificadas em um conjunto de categorias definidas a priori: ano e periódico de publicação; instituição de origem e formação do primeiro autor; natureza da autoria; natureza metodológica; e técnicas de coleta. Somente a categoria relativa aos temas dos artigos foi desenvolvida a posteriori, com base na leitura dos trabalhos. Dois pesquisadores classificaram todas as publicações nas categorias e, em caso de discordância, um terceiro ajudou na categorização. Ao final, foram calculadas as frequências de ocorrência e respectivas porcentagens para cada categoria, cujos resultados serão expostos na seção "Caracterização geral dos estudos".

Por fim, realizou-se uma análise qualitativa envolvendo somente estudos empíricos que focalizassem o tema dos conhecimentos e das crenças de professores. Tomou-se como corpus de análise os resultados desses artigos, tanto descritivos quanto interpretativos. Em alguns, os resultados apareciam separadamente em seções de resultados (descritivos) e discussão (interpretativos), já em outros, apareciam de forma mesclada em uma única seção. Foi empregada uma Análise Qualitativa de Conteúdo (BARDIN, 2010; LAVILLE; DIONNE, 1999), seguindo um modelo aberto, ou seja, com categorias definidas a posteriori, a partir dos próprios dados. Os resultados dessa análise serão expostos na seção "Análise qualitativa dos estudos empíricos sobre conhecimentos e crenças".

\section{RESULTADOS E DISCUSSÃO}

\section{Caracterização geral dos estudos}


Os 101 artigos foram publicados ao longo de 16 anos, sendo o mais antigo de 2001 e o mais recente de 2016. No período entre 2001 e 2008, foram encontrados 21 trabalhos (20\%) e, entre os anos de 2009 e 2016, 80 artigos (80\%).

Esses resultados indicam que os estudos que tratam da formação de professores na perspectiva da Educação Inclusiva ainda são muito recentes no país. Além disso, verifica-se um considerável aumento na produção nos últimos oito anos analisados, cujo início coincide com o ano da publicação da Política Nacional de Educação Especial na Perspectiva da Educação Inclusiva (BRASIL, 2008). Embora tenha sido resultado de um movimento que teve início na década anterior, tal documento certamente marcou a adesão do país ao paradigma da Educação Inclusiva, instaurando a urgente necessidade de reorganização do sistema escolar e, consequentemente, de repensar a formação de professores, o que talvez explique o maior número de estudos associado à data de publicação da política.

Interessava-nos também verificar a partir de qual área essa discussão vinha sendo predominantemente feita no país. Por isso, identificamos os periódicos, as instituições de origem dos autores e as áreas do conhecimento as quais pertenciam. Os dois periódicos que mais se destacaram foram a Revista Brasileira de Educação Especial (Associação Brasileira de Pesquisadores em Educação Especial - ABPEE/UNESP/Marília), com 20 artigos (20\%), e a Revista Educação Especial (UFSM/Santa Maria), com 18 artigos (18\%). O terceiro periódico com mais publicações foi a Revista Centro de Educação (UFSM), com seis artigos (6\%), seguido de outros três: Revista Educação (UFSM), com cinco artigos (5\%), Educar em Revista (UFPR/Curitiba), com quatro artigos (4\%), e Ciência e Educaşão (UNESP/Bauru), também com quatro artigos (4\%). Outros 32 periódicos foram identificados, em sua maioria apenas com uma publicação.

Com relação à instituição de origem dos primeiros autores, é interessante notar que houve destaque para aqueles escritos por profissionais vinculados à Universidade Federal de Santa Maria (UFSM) $(f=11)$ e à Universidade Estadual Paulista "Júlio de Mesquita Filho" (UNESP) $(f=10)$, as quais são responsáveis pelos periódicos com maior número de publicações. É possível que esses dados reflitam a força dos programas de pós-graduação aos quais os periódicos e os autores de maior destaque estão vinculados: o Programa de Pós-graduação em Educação da UNESP/Marília e o Programa de Pósgraduação em Educação da UFSM, ambos com linhas de pesquisa específicas na área da Educação Especial. Vale destacar, ainda, que a UNESP mantém um Departamento de Educação Especial como parte da Faculdade de Filosofia e Ciências, e que a UFSM oferece um curso de Licenciatura em Educação Especial, vinculado ao Centro de Educação.

Mais do que discutir as particularidades dessas instituições e cursos, cabe ressaltar que muito da produção sobre a formação de professores na perspectiva da Educação Inclusiva vem sendo feita a partir da Educação Especial. Isso se justifica, talvez, por um esforço da própria área em se repensar e encontrar um novo espaço, considerando as mudanças advindas das políticas de Educação Especial em nosso país a partir do paradigma da Educação Inclusiva (GARCIA, 2013). Parece-nos que o grande desafio da Educação Especial é poder reinventar-se, de modo a ser coerente com os princípios da Educação Inclusiva, sem, no entanto, perder seu valor e especificidades, que refletem lutas históricas pelos direitos dos alunos com deficiência. Além disso, acreditamos que essa área, por sua tradição, tem, de fato, muito a contribuir para a formação dos professores que atuam nas escolas regulares, embora também seja importante que outras áreas travem semelhante discussão, considerando a natureza essencialmente transversal e interdisciplinar que caracteriza a Educação Inclusiva.

Quanto a esse último aspecto, os dados fornecem indícios de que ainda há um longo caminho a ser trilhado, já que houve grande predomínio da Educação como área de titulação dos autores. A titulação mais frequente foi a de Doutor(a) em Educação $(f=44)$, seguida de Mestre(a) em Educação $(f=14)$ e Doutor $(a)$ em Psicologia $(f=14)$. Nessa mesma direção, verificou-se que a discussão sobre a temática tem sido feita mais por autores de uma mesma instituição: 70 artigos (70\%) são de natureza intrainstitucional e $31(30 \%)$ de caráter interinstitucional.

Com relação à natureza metodológica dos estudos, predominaram publicações envolvendo levantamento de dados $(f=57)$, ou seja, estudos de caráter exploratório-descritivo, que investigaram determinada temática em um grupo de participantes. A segunda natureza mais frequente foram os estudos de revisão não sistemática da literatura $(f=28)$. Quanto às técnicas de coleta de dados, predominou a entrevista $(f=27)$, seguida de questionário $(f=17)$ e de estudos que combinaram duas ou 
mais técnicas $(f=11)$. Em uma parte considerável dos artigos, não se aplicou qualquer técnica de coleta de dados $(f=33)$, já que se tratava de revisões de literatura (sistemáticas ou não).

Os aspectos metodológicos dos artigos parecem indicar, como era de se esperar, que o tema da formação de professores na perspectiva da Educação Inclusiva, por ser recente, vem sendo discutido de forma mais exploratória, seja com pesquisas de levantamento, seja com reflexões teóricas. Sem desmerecer o valor desses estudos, percebe-se que ainda são raros aqueles que utilizam delineamentos mais complexos, que envolvem, simultaneamente, diferentes técnicas de coleta e análise de dados, buscando uma abordagem mais explicativa ao fenômeno em questão. Por exemplo, pouco se discute sobre fatores que influenciam o processo de formação.

$\mathrm{Na}$ Tabela 1, estão descritos os temas encontrados nos artigos e suas respectivas frequências. Ressalta-se que o total de frequências não corresponde ao número total de artigos, pois alguns deles relacionavam-se, ao mesmo tempo, com mais de um tema.

Tabela 1 - Temas focalizados nos artigos e suas respectivas frequências

\begin{tabular}{|l|c|}
\hline \multicolumn{1}{|c|}{ Temas } & $\boldsymbol{f ( \% )}$ \\
\hline Aspectos teóricos da formação de professores (modelos de formação) & $33(28)$ \\
\hline Crenças de professores (valores, atitudes, imaginário, opiniões) & $31(26)$ \\
\hline Conhecimentos de professores & $19(16)$ \\
\hline Metodologias de formação/relato de experiências formativas & $17(14)$ \\
\hline Aspectos históricos e políticos da formação de professores & $9(8)$ \\
\hline $\begin{array}{l}\text { Organização curricular de cursos de formação (graduação, formação } \\
\text { complementar, pós) }\end{array}$ & $5(4)$ \\
\hline Aspectos emocionais do professor & $2(2)$ \\
\hline Nível de formação do professor (titularidade máxima) & $1(1)$ \\
\hline Outros & $1(1)$ \\
\hline TOTAL & $118(100)$ \\
\hline
\end{tabular}

Fonte: elaborada pelas autoras.

Destacaram-se artigos relacionados a aspectos teóricos da formação de professores, os quais, em geral, realizaram discussões sobre diferentes modelos formativos no campo da Educação Inclusiva. Por exemplo, o estudo de Greguol, Gobbi e Carraro (2013) abordou os modelos brasileiro e italiano de formação de professores para atuar com o público-alvo da Educação Especial, a partir de uma pesquisa documental, analisando textos legais de ambos os países.

Com semelhante frequência, também tiveram destaque as publicações que investigaram as crenças dos professores sobre a Educação Inclusiva. Estas, junto aos estudos sobre os conhecimentos dos professores, representaram $46 \%$ do total de temas identificados. Esses estudos não serão exemplificados aqui, pois são foco específico da análise qualitativa que será apresentada mais adiante.

Por fim, um quarto tema mais saliente entre os estudos foram as metodologias de formação e/ou relato de experiências formativas (14\%). Nessas pesquisas, buscou-se avaliar, por meio de investigações ou relatos de experiências, as contribuições de diferentes estratégias metodológicas para a formação de professores no campo da Educação Inclusiva. Por exemplo, o estudo de Toledo e Vitaliano (2012) investigou a eficácia de um programa de formação de professores baseado nos princípios da pesquisa colaborativa, visando a favorecer a inclusão de alunos com deficiência intelectual.

Levando em conta as principais temáticas dos estudos, entende-se que as discussões científicas na área, até então, centram-se em refletir sobre a efetividade e a qualidade da formação docente no campo da Educação Inclusiva. Isso é feito por meio da análise documental e/ou reflexões puramente teóricas, da apresentação, avaliação e discussão de diferentes experiências concretas de formação, ou, então, da análise das crenças e dos conhecimentos dos professores, que, em última instância, visa a verificar os resultados ou os impactos da formação docente. A seguir, os estudos centrados nas crenças e nos conhecimentos dos professores serão explorados com mais profundidade.

\section{Análise qualitativa dos estudos empíricos sobre conhecimentos e crenças}


Ao selecionarmos apenas os estudos empíricos sobre os conhecimentos e as crenças dos professores, verificamos que eles focalizavam diferentes públicos-alvo do processo de inclusão. Diante disso, optou-se por restringir a análise qualitativa somente às pesquisas que não focalizavam um tipo de deficiência ou NEE em particular (p. ex., deficiência visual), pois o foco não era, neste estudo, discutir aspectos particulares de determinada condição, mas sim questões gerais da formação do professor na perspectiva da Educação Inclusiva.

\section{Estudos sobre os conhecimentos dos professores}

Entre 18 estudos sobre conhecimentos dos professores sobre a Educação Inclusiva, foram corpus da análise somente nove publicações, as quais focalizaram alunos com deficiência e/ou NEE em geral (AGUIAR; DUARTE, 2005; BARRETO et al., 2013; FALKENBACH et al., 2008; GORGATTI et al., 2008; LOCKMANN, 2014; OLIVEIRA et al., 2011; OLIVEIRA; SOUZA, 2011; RAMOS et al., 2013; TERRA; GOMES, 2013). No que diz respeito ao seu objetivo, todas se tratavam de investigações sobre a formação docente frente ao processo de inclusão, compreendendo os conhecimentos do professor como um aspecto da formação. Chamou a atenção que cinco deles investigaram a temática no contexto da Educação Física, o que pode indicar que essa área tem realizado esforços adicionais nessa direção.

A Análise de Conteúdo indicou três categorias, denominadas de: 1) (Des)conhecimento sobre legislação e princípios da Educação Inclusiva; 2) Fatores associados à falta de conhecimento dos professores; e 3) Fontes do conhecimento. A seguir, elas serão apresentadas e ilustradas, eventualmente, por trechos retirados dos artigos (falas dos participantes dos estudos ou afirmações dos autores).

\section{1) (Des)conhecimento sobre legislação e princípios da Educação Inclusiva}

Nesta categoria foram incluídos os conteúdos relacionados ao conhecimento dos professores a respeito dos aspectos legais e dos princípios básicos da Educação Inclusiva. A literatura apontou indícios de que há desconhecimento a respeito da legislação específica sobre a Educação Inclusiva de nosso país, segundo a percepção dos próprios professores (OLIVEIRA; SOUZA, 2011; TERRA; GOMES, 2013). Eles afirmam que é mais comum conhecerem documentos gerais relacionados ao campo da Educação, como o Estatuto da Criança e do Adolescente (ECA), a Lei de Diretrizes e Bases da Educação Nacional (LDBEN) e a Constituição Federal, mas não os relacionados de forma particular à inclusão. Considerando que vários desses documentos apresentam não só determinações e orientações, mas também conceitos e princípios ligados à Educação Inclusiva, não é de se estranhar que os estudos também revelem poucos conhecimentos ou discursos empobrecidos dos professores sobre esses aspectos.

Ou seja, é possível que haja desconhecimento sobre quais conteúdos são apresentados na legislação, de modo que não há grande interesse em conhecê-la, o que pode repercutir nos conhecimentos gerais dos professores sobre os princípios da Educação Inclusiva. Nesse sentido, Aguiar e Duarte (2005) verificaram que, ao serem questionados sobre o que entendiam a respeito da inclusão, $70 \%$ dos professores de Educação Física participantes do estudo deram respostas equivocadas. O restante dos educadores demonstrou algum conhecimento básico, sendo que alguns deram respostas mais completas, como: "A adaptação do espaço escolar para receber essa pessoa. Respeito aos limites e diferenças por parte de todos. Apoio de um corpo técnico especializado" (AGUIAR; DUARTE, 2005, p. 233).

Nessa resposta é possível identificar diferentes princípios que caracterizam a Educação Inclusiva, desde aqueles mais filosóficos, como o respeito às diferenças, até os de cunho estrutural e pedagógico, como a adaptação do espaço físico e dos recursos, com apoio de profissionais especialistas (BRASIL, 2008). Entendemos que é de fundamental importância que todos esses aspectos sejam devidamente trabalhados no processo de formação de professores, uma vez que a ausência de qualquer um deles pode impor barreiras à verdadeira inclusão.

De forma mais específica, alguns estudos investigaram os conhecimentos dos professores em relação às intervenções pedagógicas inclusivas, ou seja, sobre os princípios básicos do trabalho junto aos alunos. Quando questionados de maneira geral sobre o assunto, os professores afirmaram não saber como agir ou mesmo que não se sentiam preparados para esse trabalho (AGUIAR; DUARTE, 2005; 
BARRETO et al., 2013), o mesmo ocorreu quando responderam a questões específicas sobre seus conhecimentos em relação a avaliação, planejamento, seleção de atividades, etc. (RAMOS et al., 2013). Por sua vez, constatou-se que, entre os professores que afirmaram saber como realizar o trabalho de inclusão, muitos deram respostas genéricas, como “[...] conscientização de todos os alunos"; “[...] preparo, estudo e naturalidade" (AGUIAR; DUARTE, 2005, p. 235).

Ressalta-se que esses três últimos estudos citados tiveram como foco professores de Educação Física, que têm desafios peculiares em seu trabalho. No entanto, seus resultados aproximamse aos de outros estudos que envolveram professores de outras áreas. Por exemplo, Lockmann (2014) investigou as estratégias pedagógicas utilizadas por professores no processo de inclusão de alunos com deficiência e/ou NEE. Um dos importantes achados da autora foi o de que:

\begin{abstract}
No decorrer da análise, o que consegui perceber não foram práticas desenvolvidas pela escola, ou pelos professores, no que se refere às suas intervenções e práticas de ensino. No lugar disso, o que encontrei foram descrições sobre os encaminhamentos que a escola realizou para cada aluno, a um conjunto de outros profissionais especializados em áreas diversas. Há, portanto, certo silenciamento das práticas de ensino e uma pulverização das práticas de encaminhamento, uma espécie de proliferação discursiva sobre as formas de atendimento oferecidas aos alunos. (LOCKMANN, 2014, p. 286).
\end{abstract}

Dessa forma, o estudo da autora aponta que o desconhecimento sobre as intervenções pedagógicas inclusivas pode levar a uma ênfase excessiva nos encaminhamentos como único recurso que o educador possui para auxiliar os alunos. Ou, então, como constatado por Falkenbach et al. (2008), tal desconhecimento pode levar os professores a sugerirem um atendimento especializado, ainda que dentro da escola regular: "[...] acho que dentro da escola tinha que existir aulas de educação física só para especiais" (FALKENBACH et al., 2008, p. 5).

Essa última fala revela, por um lado, o desconhecimento de que, do ponto de vista legal e dos princípios da Educação Inclusiva, não se pode mais conceber classes ou aulas especiais dentro da escola regular. Por outro lado, revela também, segundo os próprios autores do artigo, que, talvez, os professores percebam-se tão desprovidos de conhecimentos sobre como trabalhar pedagogicamente a inclusão, que não veem outra saída a não ser um trabalho especializado junto aos alunos.

Em nossa concepção, as práticas pedagógicas inclusivas não são somente aquelas dirigidas, especificamente, a alunos com deficiência e/ou NEE (FERREIRA, 2007). Elas incluem uma gama de ações voltadas a viabilizar um ambiente de aprendizagem plural, no qual as diferenças são tomadas como centro dos processos de ensino e aprendizagem e não como desvios que exigem adaptações e reabilitação, mantendo-se como pano de fundo o mesmo modelo tradicional de educação (MARQUES, 2006). Não se trata, como argumenta Rozek (2009), de exaltar os diferentes, colocando-os na vitrine e atribuindo à escola o título de "inclusiva". $\mathrm{Na}$ verdade, a diversidade assume um valor educativo essencial para a transformação da escola como um todo (SÁNCHEZ, 2005).

Nesse contexto, embora saibamos que conhecer as especificidades de cada deficiência e/ou NEE pode qualificar a ação pedagógica, isso, por si só, não garante o sucesso da inclusão, especialmente porque ter uma deficiência e/ou NEE não define aquilo que o sujeito é e como se relaciona com o desafio da aprendizagem. Assim, por mais que alguns estudos apontem que os professores desconhecem critérios diagnósticos e as características da deficiência (GORGATTI et al., 2008; OLIVEIRA; SOUZA, 2011; RAMOS et al., 2013), entendemos que, de acordo com os princípios fundamentais da Educação Inclusiva, essa não deve ser uma barreira para o processo de inclusão.

Acreditar que práticas pedagógicas inclusivas são somente aquelas superespecializadas, que dependem de aparatos e recursos tecnológicos complexos, pode ter feito os professores, no contexto da pesquisa, afirmarem que têm poucos conhecimentos sobre a Educação Inclusiva. Dessa forma, é importante ressaltar o desafio de mensurar aquilo que os educadores sabem apenas perguntando-lhes por meio de questões abertas. Nessa lógica, é possível que muitas práticas pedagógicas não sejam citadas no contexto da pesquisa, embora sejam coerentes com os princípios da Educação Inclusiva. Sugerimos, assim, que novos estudos investiguem seus conhecimentos de maneira mais sistemática e contextualizada.

2) Fatores associados à falta de conhecimento dos professores 
Como já mencionado, os estudos aqui analisados investigaram de forma mais ampla e exploratória os conhecimentos dos professores sobre a Educação Inclusiva. O mesmo ocorreu em relação aos fatores associados à falta de conhecimentos. Na verdade, nenhum estudo explorou especificamente essa questão, embora em alguns tal conteúdo tenha aparecido na análise do material coletado.

Por exemplo, alguns professores mencionaram que a falta de experiência no trabalho com alunos com deficiência e/ou NEE explicava seu conhecimento restrito sobre a área (OLIVEIRA et al., 2011; OLIVEIRA; SOUZA, 2011). Embora seja crescente o número de matrículas desses alunos em todas as etapas de escolarização em nosso país (BRASIL, 2017), ressalta-se, como já mencionado, que foi somente em 2008 que se estruturou de forma oficial uma política de Educação Inclusiva no Brasil e, apenas em 2015, por meio da Lei Brasileira de Inclusão da Pessoa com Deficiência (BRASIL, 2015), se tornou ilegal negar matrícula e condições de permanência com qualidade aos alunos com deficiência no sistema regular de ensino.

Isso indica que muitos professores ainda não tiveram qualquer contato com alunos com deficiência, tanto na escola quanto na universidade, como indicou o estudo de Oliveira et al. (2011). Além disso, é possível que também não tenham convivido com esses sujeitos fora do ambiente escolar, uma vez que, até hoje, sua participação na vida em sociedade é limitada por barreiras atitudinais e estruturais (FREITAS et al., 2015). Considerando esses aspectos, não se pode negar que a ausência de convivência contribua para um menor conhecimento dos professores sobre a Educação Inclusiva. Isso porque interagir com esses sujeitos é uma fonte importante de conhecimentos, não somente sobre as características da deficiência e/ou NEE, mas sobretudo a respeito de si mesmo como educador, ou seja, sobre suas limitações, sentimentos e crenças em relação a esses alunos.

Para alguns professores, o que ajudaria a ampliar seus conhecimentos, na ausência da experiência real, seriam as oportunidades de formação (AGUIAR; DUARTE, 2005; BARRETO et al., 2013; OLIVEIRA et al., 2011; OLIVEIRA; SOUZA, 2011). Alguns afirmaram que têm boa vontade para o trabalho, mas que isso não é suficiente.

A formação, nesse sentido, quando aliada a uma atitude favorável do professor frente ao trabalho com a inclusão, pode potencializar sua ação pedagógica e, sendo esta efetiva, tornar suas atitudes ainda mais favoráveis. No entanto, para Aguiar e Duarte (2005), tais formações não devem somente focalizar aspectos teóricos que envolvem a Educação Inclusiva, mas sobretudo as práticas pedagógicas que a sustentam. Daí a necessidade de formadores que tenham experiências nesse âmbito. Concordamos com esse aspecto, embora com a ressalva de que não se pode cair no extremo oposto da pura teoria, focalizando, de forma descontextualizada e acrítica, a aplicação de técnicas e recursos. Ou seja, pensar o fazer pedagógico não significa resumi-lo a um conjunto de atividades, mas sim refletir sobre as concepções de educação, ensino e aprendizagem que ancoram as práticas nas escolas e, a partir disso, construir novas possibilidades, que não estão prontas, o que tem sido denominado de uma formação com viés crítico-reflexivo (NÓVOA, 1995; PÉREZ GOMES, 1995).

Enfrentar o desafio da inclusão de forma séria e comprometida é, sem dúvida, fundamental. Entendemos como simplista a culpabilização individual dos professores em relação aos poucos conhecimentos que ainda têm na área. Assim, quando os educadores revelam suas angústias nesse sentido, não estão meramente falando de si mesmos, mas de um sistema que ainda está se estruturando para concretizar, no chão das escolas e das universidades, um trabalho verdadeiramente inclusivo. E esse processo não tem ocorrido sem contradições, já que, como apontam Michels e Garcia (2014), há indícios de que o sistema de Educação Inclusiva brasileiro tenha se constituído também a partir do argumento de ser menos oneroso do que criar um sistema complexo de escolas especializadas para grupos distintos de alunos.

Embora isso possa ser verdadeiro, sabemos que a real inclusão envolve uma gama de investimentos, sobretudo nos professores regulares e profissionais especializados, para que possam ter condições favoráveis de trabalho (DE JESUS; EFFGEN, 2012). Tais condições implicam, por um lado, a contratação de profissionais e, por outro, sua formação contínua dentro da escola, ou seja, horários disponíveis e a construção de uma cultura institucional que os apoie para momentos coletivos de debate, reflexão e realização de um adequado planejamento pedagógico. 


\section{3) Fontes do conhecimento}

Infelizmente, não é isso que os estudos aqui analisados revelam no que diz respeito às fontes nas quais os professores têm buscado conhecimentos. O que se verifica, pelo contrário, são iniciativas individuais que envolvem, por exemplo, leituras independentes (AGUIAR; DUARTE, 2005), conversas informais com colegas e buscas na internet (RAMOS et al., 2013). Esses últimos autores refletem que esse tipo de desenvolvimento profissional, mais autônomo, normalmente predomina quando a formação inicial é de baixa qualidade ou inexistente no que diz respeito à determinada temática.

Esse pode ser o caso dos conhecimentos relacionados à Educação Inclusiva, já que apenas um estudo constatou que a formação inicial era uma importante fonte de conhecimento para alguns professores, que haviam finalizado sua graduação mais recentemente (RAMOS et al., 2013). Sabe-se que somente a partir de 1994 (BRASIL, 1994) passou a ser obrigatória, no Brasil, a inserção de disciplinas ligadas ao campo da Educação Inclusiva nos cursos de graduação voltados à formação de professores. No entanto, mesmo assim, essas temáticas são exploradas de forma eletiva ou isolada, e são pouco articuladas com outras disciplinas afins, como as do campo da Didática, das Teorias do Desenvolvimento e Aprendizagem e dos estágios práticos, o que acaba por fragilizar o processo formativo, deixando lacunas importantes.

Não estamos defendendo a ideia de que toda a formação se encerra na graduação, mas que a formação inicial tem um papel relevante na promoção de atitudes mais favoráveis ao processo de inclusão (FONSECA-JANES; OMOTE, 2013). Ingressar no mundo profissional aberto a esse paradigma educacional é um primeiro passo para que o professor possa ter desejo de se envolver em outras oportunidades de aprendizagem, aí sim mais diretamente ligadas à sua prática cotidiana.

Em contrapartida, cabe às instituições valorizarem e favorecerem essas oportunidades, o que ainda é um desafio. Nesse sentido, Falkenbach et al. (2008, p. 5) constataram que "há um sentimento de isolamento dos professores em sua prática educativa. Foi frequente escutar dos professores o quanto necessitam de apoio e de discussões sobre o tema". Mais adiante, os autores continuam afirmando que "caso a escola continuar insistindo em um modelo individualista de pensar, a segregação e o isolamento dos professores debilita qualquer tentativa de inclusão" (FALKENBACH et al., 2008, p. 5).

Assim como esses autores, também entendemos que não se pode constituir uma escola inclusiva sem que todos possam sentir-se parte da comunidade escolar e aprendizes, inclusive os professores.

Estudos sobre as crenças dos professores

De 28 estudos empíricos sobre as crenças dos professores a respeito da Educação Inclusiva, foram considerados, para a análise qualitativa, 16 publicações, as quais focalizaram alunos com deficiência e/ou NEE em geral (ÁVILA; TACHIBANA; VAISBERG, 2008; FALKENBACH et al., 2008; FONSECA-JANES; OMOTE, 2013; FREITAS, 2011; GOMES; GONZÁLEZ REY, 2007; GORGATTI et al., 2008; NAUJORKS, 2002; OLIVEIRA et al., 2012; OMOTE et al., 2005; RUSSO; COUTO; VAISBERG, 2005; SANT'ANA, 2005; SCHERER, 2015; SOUZA; SILVERO; GALHARDI, 2015; VILELA-RIBEIRO; BENITE, 2010, 2013; VITTA; VITTA; MONTEIRO, 2010).

A maioria destes $(n=12)$ teve como objetivo caracterizar as crenças dos professores (ou, em alguns casos, também de diretores e futuros professores) sobre o processo de inclusão escolar, envolvendo aspectos como o seu entendimento sobre o conceito de Educação Inclusiva, desafios e dificuldades implicadas no processo de inclusão e crenças sobre a efetividade da Educação Inclusiva. Outro objetivo dos estudos $(n=4)$ foi descrever as crenças dos educadores sobre os sujeitos com deficiência e/ou NEE, incluindo, por exemplo, como definiam a deficiência e/ou a NEE. Por fim, duas pesquisas investigaram em que medida a formação contribui para a mudança das crenças dos professores sobre o processo de inclusão, seja a formação inicial na graduação, seja em cursos específicos.

A Análise de Conteúdo dos artigos indicou quatro categorias de crenças sobre: 1) a definição de Educação Inclusiva; 2) o(s) sujeito(s) com deficiência e/ou NEE; 3) a efetividade da Educação Inclusiva; e 4) os fatores determinantes na efetividade dos processos inclusivos. 


\section{1) Crenças sobre a definição de Educação Inclusiva}

Os estudos revelaram dois entendimentos a respeito da Educação Inclusiva. Por um lado, acredita-se que está relacionada à socializaç̧ão da pessoa com deficiência e/ ou NEE, visão que pareceu ser a mais comum. Os professores enfatizaram, por exemplo, que incluir significa muito mais compartilhar o mesmo espaço físico (SANT'ANA, 2005), conviver com os outros e mostrar-se prestativo na escola (GOMES; GONZÁLEZ REY, 2007). Essa crença associa-se à ideia de que os alunos com deficiência e/ou NEE não podem aprender, de modo que o papel da Educação Inclusiva seria muito mais viabilizar a convivência do que a aprendizagem e o desenvolvimento efetivo desses sujeitos.

Uma fala de uma professora que ilustra bem essa crença foi citada no estudo de Gomes e González Rey (2007, p. 413): “A vinda dele é só para que conviva com os outros; tudo bem que ele ajuda, varre a sala, mas não tem como haver aprendizado". Para esses autores, tal perspectiva estaria sustentada em uma ideia de ensino e aprendizagem como processos burocráticos, que delimitam, massificam e padronizam o desenvolvimento humano. Ou seja, que desconsideram os processos subjetivos singulares dos sujeitos implicados no ensinar e no aprender.

Assim, restaria à Educação Inclusiva uma missão muito mais humanitária do que educacional (GOMES; GONZÁLEZ REY, 2007; VITTA; VITTA; MONTEIRO, 2010), o que também esteve presente nas crenças dos diretores participantes do estudo de Sant'ana (2005), os quais enfatizaram a integração na sociedade como sendo o foco do processo de inclusão.

Dessa forma, podemos pensar que, para que a Educação Inclusiva seja vista de uma perspectiva educacional, são necessárias outras concepções de sujeito, de ensino e de aprendizagem que considerem a diversidade como constitutiva desses processos, resgatando o caráter ético-político que caracteriza o projeto educativo na modernidade (DIAS, 2006; MARQUES, 2006). Caso contrário, conforme apontado por Dias (2006), corre-se o risco de considerar a inclusão muito mais como um projeto moralista, que inferioriza os sujeitos que constituem o grupo dos "incluídos", seja pelas oportunidades empobrecidas de aprendizagem, seja porque "se achem no direito de ter privilégios e posições de exceção em relação aos outros” (DIAS, 2006, p. 36).

Somente com o rompimento dessa concepção é possível entender a Educação Inclusiva como promoção da aprendizagem da pessoa com deficiência elou NEE, o que também foi identificado nos estudos, embora com menor ênfase. Gomes e González Rey (2007) verificaram que, para um grupo pequeno de professores, incluir significa modernizar as práticas educacionais, visando ao respeito às diferenças dos alunos. Além disso, para que isso ocorra, é necessário um investimento afetivo do educador em relação ao aluno, no sentido de incentivar, cobrar, dar limites e não negligenciar, tal como relatado por uma professora do mesmo estudo: "Se der uma forçada nele, ele vai, o problema é que todo mundo deixa ele fazer o que quer, e, quando ele vê a dificuldade, sabe que não precisa enfrentar... é mais fácil para muitos professores, deixar ele fora da sala, pois daí não dá trabalho" (GOMES; GONZÁLEZ REY, 2007, p. 411).

Ser professor é uma tarefa que exige disposição e, quanto a isso, é importante ressaltar que: “[...] boas práticas inclusivas exigem, em última análise, a adoção de mudanças e acomodações ao nível dos materiais e a planificação de atividades, estratégias de ensino e organização da sala de aula [...]" (FERREIRA, 2007, p. 86). Assim, deixar o aluno fazer o que quer mostra uma atitude excludente do professor, pois desobrigá-lo de fazer qualquer tipo de tarefa significa tratá-lo com descaso, tornando-o mais inseguro e dificultando ainda mais seu processo de aprendizagem (GOMES; GONZÁLEZ REY, 2007).

Crença semelhante foi identificada no estudo de Vilela-Ribeiro e Benite (2013), os quais entrevistaram professores universitários formadores de professores. Para eles, incluir significa transpor barreiras para que as pessoas com deficiência e/ou NEE possam permanecer na escola, aprender e se desenvolver. Os autores discutem que, muitas vezes, essas barreiras têm a ver com a necessidade de reflexão e de redimensionamento das práticas educativas, de modo a modificar o olhar do professor sobre as possibilidades de aprender de cada sujeito, tema que se relaciona à próxima categoria.

2) Crenças sobre o(s) sujeito(s) com deficiência e/ou NEE 
Alguns estudos analisados focalizaram as crenças dos professores a respeito do sujeito com deficiência e/ou NEE. Nesse sentido, houve predomínio de um viés individual/ biológico/patologizante, ou seja, ao falar sobre esses sujeitos, os participantes enfatizaram aspectos como seu diagnóstico científico, seja como critério de organização de turmas homogêneas em escolas regulares (OLIVEIRA et al., 2012), seja como leitura inicial que se faz sobre o sujeito, a qual "oferece explicações antecipadas ao inusitado aluno" (SCHERER, 2015). Ainda nesse viés, também foram vinculadas à deficiência as noções de incapacidade, diferença e anomalia (SCHERER, 2015; VITTA; VITTA; MONTEIRO, 2010).

Assim, nesse primeiro conjunto de crenças, a deficiência e/ou NEE é vista como algo inerente ao sujeito, que lhe pertence, ligado a uma patologia, cuja origem estaria em processos biológicos (ainda que nem sempre visíveis). É o que a literatura tem denominado de perspectiva direta ou médica da deficiência (GESSER; NUERNBERG; TONELI, 2012; OMOTE, 1996).

Ocorre que, muitas vezes, essa perspectiva da deficiência desencoraja a interação social com esses sujeitos, tal como enfatizado por Silva et al. (2012, p. 163):

\begin{abstract}
Muitas vezes a percepção errônea sobre o aluno se deve ao próprio tipo de deficiência. A dificuldade em coordenar os movimentos e controlar posturas, os déficits de aprendizagem, as disfunções fonoarticulatórias podem provocar impressões subjetivas equivocadas sobre este aluno e, com isto, desencorajar interações sociais, impedindo o desenvolvimento de processos proximais.
\end{abstract}

Outro viés relacionado a esse primeiro é o tecnicista, identificado também em alguns estudos analisados (ÁVILA; TACHIBANA; VAISBERG, 2008; RUSSO; COUTO; VAISBERG; 2009). A partir de histórias e desenhos produzidos pelos participantes, essas pesquisas constataram que os alunos com deficiência e/ou NEE foram descritos "[...] em termos de suas capacidades e incapacidades, e não como um ser humano integrado" (ÁVILA; TACHIBANA; VAISBERG, 2008, p. 158).

Para os autores, isso pode ser explicado em função de o contexto escolar ser marcado por uma cultura avaliativa tradicional, que classifica os sujeitos de acordo com seus sucessos e insucessos. Esse afastamento do humano integrado também se apresenta quando os professores descrevem a pessoa com deficiência como "[...] objeto de ações essencialmente técnicas" (RUSSO; COUTO; VAISBERG, 2009, p. 253).

Essa é uma questão bastante complexa que merece nossa atenção, especialmente quando relacionada à formação de professores. Não se trata apenas de um tema específico ao campo da Educação Inclusiva, embora este deflagre com mais evidência o quanto estamos nos afastando do aspecto humano que caracteriza os processos educativos. $\mathrm{O}$ apelo às técnicas tem menosprezado o papel da interação social na aprendizagem e tudo que a caracteriza, em especial os aspectos emocionais e cognitivos. Por exemplo, os sistemas de apostilas e recursos didáticos padronizados, que muitas escolas têm adotado, retiram do professor grande parte de seu protagonismo na elaboração de ferramentas de ensino que sejam coerentes com os sujeitos da aprendizagem e que também os coloquem como corresponsáveis nesse processo.

Dessa forma, quando um professor é convocado a ensinar um sujeito com deficiência e/ou NEE, é possível que, diante da estranheza frente ao desconhecido, a necessidade de recorrer a algo técnico seja ainda mais intensa. A técnica (diagnóstico e outros recursos concretos) talvez funcione como uma barreira inicial necessária que, apesar de afastar, ao mesmo tempo viabiliza o contato com o desconhecido (ÁVILA; TACHIBANA; VAISBERG, 2008; SCHERER, 2015). Nesse sentido, Scherer (2015, p. 313) afirma que, por um lado, a partir dessa lógica, cabe ao professor

[...] apenas executar técnicas e atividades predeterminadas, sem se responsabilizar pela construção do processo educativo. Entretanto, após o impacto inicial, essa leitura parece ser uma possibilidade para preencher o nada que se apresenta no primeiro encontro do professor com o aluno, em uma tentativa de torná-lo menos desarmônico.

Não se trata, portanto, de negar a importância dos aspectos técnicos no processo de inclusão. Contudo, não se pode resumir a inclusão à definição de um diagnóstico e de recursos mínimos que permitam aos sujeitos estarem na escola (p. ex., acessibilidade física, sala de recursos, etc.). A inclusão 
verdadeira ocorre na medida em que os sujeitos são inseridos em processos humanos de aprendizagem, o que requer que sejam olhados em sua completude, em seu modo de ser e agir, em suas contradições, dentro de um contexto de relações (dentro e fora da escola). Da mesma forma, requer que o professor seja visto não como um aplicador de técnicas, mas também em sua completude, o que discutiremos mais adiante.

De forma menos expressiva, esses aspectos também apareceram nos estudos analisados. Alguns participantes, por exemplo, ao se referirem aos sujeitos com deficiência e/ou NEE, o fizeram por meio de um viés da singularidade, enfatizando a forma como essas pessoas vivenciam o processo de inclusão (ÁVILA; TACHIBANA; VAISBERG, 2008; FALKENBACH et al., 2008; RUSSO; COUTO; VAISBERG, 2009). Destacou-se, no entanto, o sofrimento como marca dessa vivência, no sentido de que estar na escola pode ser enriquecedor, mas também bastante doloroso. Russo, Couto e Vaisberg (2009, p. 252) acreditam, porém, que apesar da ênfase no sofrimento, essa forma de ver o sujeito com deficiência parece possibilitar "posturas sensíveis e cuidadosas" frente a ele.

Apesar de o viés da singularidade ter aparecido como crença dos participantes, destaca-se que isso ocorreu de forma bastante sutil e delimitada. Nenhum estudo demonstrou que a perspectiva social da deficiência tem sido efetivamente considerada nos discursos dos professores. Essa visão enfatiza o papel do contexto social (da audiência) na definição do status de "deficiência", assumindo que as diferenças adquirem valor de deficiência quando confrontadas a padrões de normalidade estabelecidos culturalmente (OMOTE, 1996; ROZEK, 2009). Dessa forma, concebe a deficiência como um campo de humanidades, uma questão de direitos humanos, para além de aspectos ligados ao corpo (GESSER; NUERNBERG; TONELI, 2012). A partir disso, entendemos que a compreensão de tal perspectiva, na medida em que relativiza o olhar sobre as deficiências, pode viabilizar uma visão mais favorável em relação à efetividade do processo de inclusão, tema da próxima categoria.

\section{3) Efetividade da Educação Inclusiva}

Os estudos que investigaram as crenças dos professores a respeito da efetividade da Educação Inclusiva, em geral, demonstraram um panorama relativamente pessimista. $\mathrm{O}$ relato de um professor, participante da pesquisa de Gomes e González Rey (2007, p. 414) ilustra bem esse quadro: "Não somos uma escola especial... já temos tantos problemas e, nesse caso, é ele que não tem como aprender; a gente tem dificuldades até com os 'normais', esses que já têm mesmo alguma coisa, daí não dá mesmo".

Verificam-se, nessa fala, duas tendências identificadas nos estudos. Por um lado, a crença de que a escola regular não é para todos, sendo que o nível de independência (física e intelectual) deveria ser considerado um critério de elegibilidade do aluno para frequentar esse ambiente (VITTA; VITTA; MONTEIRO, 2010). Por outro lado, constata-se a crença de que a escola de Educação Especial seria o local mais adequado para a educação formal das pessoas com deficiência, o que também foi verificado por Ávila, Tachibana e Vaisberg (2008), Freitas (2011) e Vilela-Ribeiro e Benite (2013).

Foi possível perceber que, ao serem questionados sobre a efetividade da Educação Inclusiva, os professores geralmente tinham como base um viés individual/biológico/patologizante sobre a deficiência e/ou NEE, tal como discutido na categoria anterior. Essa visão fatalista sobre a deficiência acaba retirando da escola regular a possibilidade de ensinar o aluno, sendo os espaços especializados, com recursos e profissionais específicos, vistos como única saída.

A crença de que a Educação Inclusiva é efetiva apareceu de forma mais sutil nos estudos, estando mais associada à ideia, também já discutida, de socialização dos alunos com deficiência e/ou NEE. Por exemplo, no estudo de Gorgatti et al. (2008), verificou-se que a maior parte dos professores participantes concordou com a ideia de que a Educação Inclusiva é benéfica para todos os estudantes, com e sem deficiência, e que, geralmente, há uma boa aceitação dos últimos em relação aos primeiros.

Porém, apesar de a efetividade da Educação Inclusiva não ter sido salientada, ressalta-se que a maioria dos professores participantes das pesquisas não se posicionou totalmente desfavorável à presença de alunos com deficiência e/ou NEE na escola regular. Seus discursos centraram-se muito mais nos fatores que poderiam contribuir para que a Educação Inclusiva se tornasse mais efetiva, foco da última categoria a ser discutida. 
4) Fatores determinantes na efetividade dos processos inclusivos

De todas as categorias, esta foi a que mais se destacou, seja pela quantidade de falas dos participantes, seja pela diversidade qualitativa de aspectos levantados. De forma geral, foi possível verificar que os professores reivindicaram condições concretas para que a educação se torne efetivamente inclusiva, indo além dos aspectos legais. Nesse sentido, em alguns estudos (NAUJORKS, 2002; VILELA-RIBEIRO; BENITE, 2013; VITTA; VITTA; MONTEIRO, 2010), o interesse político surgiu como um fator determinante nesse processo, no sentido de que não basta impor a inclusão dos alunos com deficiência e/ou NEE na escola regular, é preciso avaliar as condições reais do sistema educacional para tanto.

Discute-se que, muitas vezes, as preocupações centram-se mais nas questões políticas do que pedagógicas, sendo que, sem estas, não há inclusão de fato. Do ponto de vista pedagógico, o que se percebe é a predominância da boa vontade individual de professores. Mas, como ressaltam Vilela-Ribeiro e Benite (2013, p. 791) em relação ao contexto da Educação Superior "[...] boa vontade política e institucional também devem existir, porque, se não há políticas de qualificação dos profissionais nas instituições de Educação Superior, e se não existem, também, incentivos para que haja qualificação, é difícil que os profissionais por si só tomem a decisão".

A questão da qualificação foi outro fator considerado pelos professores como determinante na efetividade dos processos inclusivos. Nesse sentido, poder contar com uma equipe de profissionais especialistas dentro da escola foi algo muito enfatizado pelos participantes, uma vez que isso poderia facilitar o processo de formação em serviço, suprindo lacunas deixadas na formação inicial (FALKENBACH et al., 2008; GOMES; GONZÁLEZ REY, 2007; NAUJORKS, 2002; OLIVEIRA et al., 2012; SANT"ANA, 2005; VITTA; VITTA; MONTEIRO, 2010).

É interessante que os professores enfatizaram muito mais a atuação colaborativa com outros profissionais, no sentido de contarem com seu apoio para o trabalho pedagógico junto aos alunos. Em apenas um estudo apareceu, de forma explícita, a crença de que deveria haver mais profissionais especialistas (incluindo auxiliares de sala) para atender diretamente os alunos, em horários alternativos, com foco na reabilitação (VITTA; VITTA; MONTEIRO, 2010).

Isso pode estar indicando que muitos docentes compreendem o caráter educacional das políticas inclusivas e, assim, reconhecem que o papel dos profissionais especialistas na escola não é o de atuar no viés clínico, da reabilitação. Em contrapartida, como ponderam Oliveira et al. (2012), muitas vezes os profissionais da saúde que atuam dentro das escolas não têm a mesma compreensão, o que pode dificultar o trabalho colaborativo com os professores com vistas ao aprimoramento dos processos pedagógicos.

Em relação a esse aspecto, algo importante que apareceu em alguns estudos diz respeito ao investimento na pessoa do professor como fator determinante para a efetividade dos processos inclusivos. Ressalta-se que o apoio ao professor deve ir além de fornecer conhecimentos técnicos, ou seja, é preciso reconhecer a necessidade de uma sustentação emocional a ele (ÁVILA; TACHIBANA; VAISBERG, 2008, p. 162), pois, conforme afirmam esses autores, “[...] o que está sendo demandado ultrapassa a esfera cognitiva, consistindo em uma estratégia ineficaz e, em casos radicais, em uma estratégia que pode vir a reforçar um olhar mais tecnicista e desprovido de contato humano [...]".

A partir de outro viés teórico, Gomes e González Rey (2007, p. 412) também ressaltam essa questão ao se referirem à "instrumentalização e à racionalização dos elementos de sentidos subjetivos, que são singulares e individuais". Para os autores, só será possível mudar as posturas profissionais frente ao processo de inclusão se levarmos em conta a singularidade dos professores.

De certa forma, a literatura reconhece essa necessidade, ao apontar a disposição da comunidade escolar para o processo de inclusão como outro fator que influencia diretamente sua efetividade (ÁVILA; TACHIBANA; VAISBERG, 2008; NAUJORKS, 2002; SANT'ANA, 2005; VILELA-RIBEIRO; BENITE, 2010; VITTA; VITTA; MONTEIRO, 2010). Embora aqui novamente o professor tenha destaque, outras figuras da comunidade também são apontadas, como as famílias e os gestores. Há reconhecimento de que é preciso considerar os processos subjetivos de todos esses sujeitos frente à inclusão, os quais envolvem preconceitos, fantasias, emoções diversas e contradições. Poder criar espaços 
em que esses aspectos sejam escutados e discutidos é essencial para que a inclusão encontre uma via menos obstruída para sua efetivação.

Por fim, os estudos ainda apontaram que, para os participantes, alguns aspectos mais objetivos seriam imprescindíveis para tornar mais efetiva a proposta da Educação Inclusiva, tais como a redução do número de alunos por turma (GOMES; GONZÁLEZ REY, 2007; SANT'ANA, 2005) e a melhoria dos recursos materiais e das adaptações arquitetônicas na escola (GOMES; GONZÁLEZ REY, 2007; GORGATTI et al., 2008; NAUJORKS, 2002; SANT"ANA, 2005; VITTA; VITTA; MONTEIRO, 2010).

\section{CONSIDERAÇÕES FINAIS}

O presente estudo buscou mapear, de forma sistemática, a literatura científica brasileira sobre o tema dos conhecimentos e das crenças de professores em relação à Educação Inclusiva. Inicialmente, caracterizamos os estudos encontrados, de modo a identificar como a temática vem sendo explorada do ponto de vista acadêmico. Verificamos um número crescente de publicações, especialmente na última década. A Educação, em geral, destacou-se como área que vem realizando esse debate, e, de forma particular, a Educação Especial. Isso indica a importância de outras áreas da Educação também investirem no tema da formação de professores na perspectiva da Educação Inclusiva, de modo a poder tornar, de fato, essa discussão transversal no processo de formação docente. Ou seja, que no estudo da didática, do desenvolvimento e da aprendizagem, da história da Educação, por exemplo, sejam feitas essas discussões, inclusive nas licenciaturas.

Analisando com mais profundidade os estudos sobre conhecimentos e crenças dos professores, verificou-se que ainda há muito a ser feito para que a Educação Inclusiva de fato seja implementada com coerência aos seus princípios fundamentais. Conhecimentos empobrecidos ou equivocados sobre o conceito de Educação Inclusiva ainda estão presentes, de modo que seu caráter humanitário é muito mais ressaltado do que seu caráter educacional. Isso se ancora em concepções de sujeito, de deficiência e de ensino e aprendizagem marcadas pela padronização e universalização.

A escola ainda é um lugar para um sujeito ideal, universal, e não para todos. Aos diferentes resta a socialização, um olhar técnico e especializado. O professor não se sente protagonista do processo de inclusão, já que os aspectos pedagógicos que o caracterizam estão minimizados, quer nas políticas, quer na formação docente. Portanto, de forma geral, os educadores pouco acreditam na política e em si mesmos como agentes desta política. Ainda assim, a busca por formação predominantemente é de iniciativa individual dos professores. Qual Educação Inclusiva se almeja para o país? Esse debate ainda está em aberto e precisa ser feito em todas as instâncias.

\section{REFERÊNCIAS}

AGUIAR, J. S.; DUARTE, É. Educação inclusiva: um estudo na área da educação física. Revista Brasileira de Educação Especial, Marília, v. 11, n. 2, p. 223-240, maio/ago. 2005.

ÁVILA, C. F.; TACHIBANA, M.; VAISBERG, T. M. J. A. Qual é o lugar do aluno com deficiência? O imaginário coletivo de professores sobre a inclusão escolar. Paidéia, Ribeirão Preto, v. 18, n. 39, p. 155164, 2008.

BARDIN, L. Análise de conteúdo. Lisboa: Edições 70, 2010.

BARRETO, M. A. et al. A preparação do profissional de educação física para a inclusão de alunos com deficiência. Podium Sport, Leisure and Tourism Review, São Paulo, v. 2, n. 1, p. 152-167, 2013.

BRASIL. Conselho Nacional de Educação. Câmara de Educação Básica. Resolução no 2, de 11 de setembro de 2011. Institui Diretrizes Nacionais para a Educação Especial na Educação Básica. Brasília, 
DF: CNE, 2001. Disponível em: http://portal.mec.gov.br/cne/arquivos/pdf/CEB0201.pdf. Acesso em: 9 maio 2020.

BRASIL. Instituto Nacional de Estudos e Pesquisas Educacionais Anísio Teixeira (INEP). Censo Escolar da Educação Básica 2016: notas estatísticas. Brasília, DF: INEP, 2017. Disponível em: http://download.inep.gov.br/educacao_basica/censo_escolar/notas_estatisticas/2017/notas_estatistic as_censo_escolar_da_educacao_basica_2016.pdf. Acesso em: 9 maio 2020.

BRASIL. Lei no 9.394/96, de 20 de dezembro de 1996. Estabelece as diretrizes e bases da educação nacional. Disponível em: http://www.planalto.gov.br/ccivil_03/leis/19394.htm. Acesso em: 14 maio 2020.

BRASIL. Lei n ${ }^{\circ}$ 13.146, de 6 de julho de 2015. Institui a Lei Brasileira de Inclusão da Pessoa com Deficiência (Estatuto da Pessoa com Deficiência). Brasília, DF: Presidência da República, 2015. Disponível em: http://www.planalto.gov.br/ccivil_03/_ato2015-2018/2015/lei/113146.htm. Acesso em: 9 maio 2020.

BRASIL. Ministério da Educação. Portaria no 1.793, de 27 de dezembro de 1994. Dispõe sobre a necessidade de complementar os currículos de formação de docentes e outros profissionais que interagem com portadores de necessidades especiais e dá outras providências. Brasília, DF: Ministério da Educação, 1994. Disponível em: http://portal.mec.gov.br/seesp/arquivos/pdf/port1793.pdf. Acesso em: 9 maio 2020.

BRASIL. Secretaria de Educação Especial. Política Nacional de Educação Especial na Perspectiva da Educação Inclusiva. Brasília, DF, jan. 2008. [Documento elaborado pelo Grupo de Trabalho nomeado pela portaria $n^{\circ} 555 / 2007$, prorrogada pela portaria no $948 / 2007$, entregue ao ministro da Educação em 7 de janeiro de 2008]. Disponível em: http://portal.mec.gov.br/arquivos/pdf/politicaeducespecial.pdf. Acesso em: 9 maio 2020.

BUENO, J. G. S. As políticas de inclusão escolar: uma prerrogativa da educação especial? In: BUENO, J. G. S.; MENDES, G. M. L.; SANTOS, R. A. Deficiência e escolarização: novas perspectivas de análise. Araraquara, SP: Junqueira\&Marin; Brasília, DF: CAPES, 2008, p. 43-63.

COSTA, A. B.; ZOLTOWSKI, A. P. C. Como escrever um artigo de revisão sistemática. In: KOLLER, S. H.; DE PAULA COUTO, M. C. P.; VON HOHENDORFF, J. (Orgs.). Manual de produção científica. Porto Alegre: Penso, 2014. p. 55-70.

DE JESUS, D. M.; EFFGEN, A. P. S. Formação docente e práticas pedagógicas: conexões, possibilidades e tensões. In: MIRANDA, T. G.; GALVÃO FILHO, T. A. (Orgs.). O professor e a educação inclusiva: formação, práticas e lugares. Salvador: EDUFBA, 2012. p. 11-18.

DIAS, S. Educação e inclusão: projeto moral ou ético. Educação e Subjetividade, São Paulo, ano 1, n. 2, p. 17-42, 2006.

FALKENBACH, A. P. et al. A formação e a prática vivenciada dos professores de educação física com a inclusão de crianças com necessidades educacionais especiais na escola comum. Temas sobre desenvolvimento, São Paulo, v. 16, n. 92, p. 56-60, 2008.

FERREIRA, M. S. Educação regular, educação especial: uma história de separação. Porto: Edições Afrontamento, 2007. 
FONSECA-JANES, C. R. X.; OMOTE, S. Atitudes sociais em relação à inclusão: o curso de Pedagogia da Faculdade de Ciências e Tecnologia da UNESP. Nuances: estudos sobre educação, Presidente Prudente, v. 24, n. 2, p. 158-173, 2013.

FREITAS, N. K. Educação inclusiva e cidadania: aproximações e contradições. Revista Eletrônica de Educação, São Carlos, v. 5, n. 1, p. 40-56, 2011.

FREITAS, M. N. C. et al. Características psicossociais do contato inicial com alunos com deficiência. Psicologia \& Sociedade, Campinas, v. 27, n. 1, p. 211-220, 2015.

GARCIA, R. M. C. Política de educação especial na perspectiva inclusiva e a formação docente no Brasil. Revista Brasileira de Educação, Rio de Janeiro, v. 18, n. 52, p. 101-119, 2013.

GESSER, M.; NUERNBERG, A. H.; TONELI, M. J. F. A contribuição do modelo social da deficiência à psicologia social. Psicologia \& Sociedade, Campinas, v. 24, n. 3, p. 557-566, 2012.

GOMES, C.; GONZÁLEZ REY, F. L. Inclusão escolar: representações compartilhadas de profissionais da educação acerca da inclusão escolar. Psicologia: Ciência e Profissão, Brasília, v. 27, n. 3, p. 406-417, 2007.

GORGATTI, M. G. et al. Atitudes dos professores de educação física do ensino regular com relação a alunos portadores de deficiência. Revista Brasileira de Ciência e Movimento, Brasília, v. 12, n. 2, p. 6368, 2008.

GREGUOL, M.; GOBBI, E.; CARRARO, A. Formação de professores para a educação especial: uma discussão sobre os modelos brasileiro e italiano. Revista Brasileira de Educação Especial, Marília, v. 19, n. 3, p. 307-324, 2013.

LAVILLE, C.; DIONNE, J. A construção do saber: manual de metodologia da pesquisa em ciências humanas. Porto Alegre: Artmed, 1999.

LOCKMANN, K. As práticas de in/exclusão na escola e a redefinição do conhecimento escolar: implicações contemporâneas. Educar em Revista, Curitiba, n. 54, p. 275-292, 2014.

MARQUES, L. P. Implicações da inclusão no processo pedagógico. Revista Inter Ação, Goiânia, v. 31, n. 2, p. 197-208, 2006.

MENDES, E. G. Sobre alunos "incluídos" ou "da inclusão": reflexões sobre o conceito de inclusão escolar. In: VICTOR, S. L; VIEIRA, A. B.; OLIVEIRA, I. M. (Orgs.). Educação especial inclusiva: conceituações, medicalização e políticas. Campos dos Goytacazes: Brasil Multicultural, 2018, p. 58-81.

MICHELS, M. H.; GARCIA, R. M. C. Sistema educacional inclusivo: conceito e implicações na política educacional brasileira. Cadernos CEDES, Campinas, v. 34, n. 93, p. 157-173, 2014.

NAUJORKS, M. I. Stress e inclusão: indicadores de stress em professores frente à inclusão de alunos com necessidades educacionais especiais. Revista Educação Especial, Santa Maria, n. 20, p. 117-125, 2002.

NÓVOA, A. Formação de professores e profissão docente. In: NÓVOA, A. (Coord.). Os professores e a sua formação. Lisboa: Dom Quixote, 1995. p. 13-33.

OLIVEIRA, J. P. et al. Concepções de professores sobre a temática das chamadas dificuldades de aprendizagem. Revista Brasileira de Educação Especial, Marília, v. 18, n. 1, p. 93-112, 2012. 
OLIVEIRA, M. A. M.; SOUZA, S. F. Políticas para a inclusão: estudo realizado em uma escola estadual de Belo Horizonte. Educar em Revista, Curitiba, n. 42, p. 245-261, 2011.

OLIVEIRA, M. L. et al. Educação inclusiva e a formação de professores de ciências: o papel das universidades federais na capacitação dos futuros educadores. Ensaio Pesquisa em Educação em Ciências, Belo Horizonte, v. 13, n. 3, p. 99-117, 2011.

OMOTE, S. Perspectivas para conceituação de deficiências. Revista Brasileira de Educação Especial, Marília, v. 2, n. 4, p. 127-135, 1996.

OMOTE, S. et al. Mudança de atitudes sociais em relação à inclusão. Paidéia, Ribeirão Preto, v. 15, n. 32, p. 387-398, 2005.

PATTO, M. H. S. Políticas atuais de inclusão escolar: reflexão a partir de um recorte conceitual. In: BUENO, J. G. S. (Org.) Deficiência e escolarização: novas perspectivas de análise. Araraquara: SP. Junqueira \& Marin. 2008, p.25-42.

PÉREZ GOMEZ, A. O pensamento prático do professor: a formação do professor como profissional reflexivo. In: NÓVOA, A. (Org.). Os professores e sua formação. Lisboa: Dom Quixote, 1995. p. 93114.

RAMOS, V. et al. Autopercepção de competência pedagógica de professores de educação física no ensino inclusivo. Revista Brasileira de Ciência e Movimento, Brasília, v. 21, n. 2, p. 123-134, 2013.

ROZEK, M. A educação especial e a educação inclusiva: compreensões necessárias. Reflexão e Ação, Santa Cruz do Sul, v. 17, n. 1, p. 164-183, 2009.

ROZEK, M. Subjetividade, formação e educação especial: histórias de vida de professoras. 2010. 177p. Tese (Doutorado em Educação) - Universidade Federal do Rio Grande do Sul, Porto Alegre, 2010.

RUSSO, R. C. T.; COUTO, T. H. A. M.; VAISBERG, T. M. J. A. O imaginário coletivo de estudantes de educação física sobre pessoas com deficiência. Psicologia \& Sociedade, Campinas, v. 21, n. 2, p. 250 255, 2009.

SÁNCHEZ, P. A Educação inclusiva: um meio de construir escolas para todos no século XXI. Inclusão: Revista da Educação Especial, Brasília, ano I, n. 1, p. 7-18, 2005.

SANT'ANA, I. M. Educação inclusiva: concepções de professores e diretores. Psicologia em Estudo, Maringá, v. 10, n. 2, p. 227-234, 2005.

SCHERER, L. C. B. Três tempos de leitura: uma experiência em formação de professores no contexto da inclusão escolar. Estilos da Clínica, São Paulo, v. 20, n. 2, p. 310-324, 2015.

SILVA, R. L. M. et al. As propriedades do professor e do aluno com deficiência na utilização de recursos de comunicação alternativa em sala de aula comum. In: MIRANDA, T. G.; GALVÃO FILHO, T. A. (Orgs.). O professor e a educação inclusiva: formação, práticas e lugares. Salvador: EDUFBA, 2012. p. 159-177.

SOUZA, M. M. G. S.; SILVERO, A. S.; GALHARDI, C. M. Formação inclusiva: concepção de deficiência e atitudes sociais em relação à inclusão de estudantes de Psicopedagogia. Tecer, Belo Horizonte, v. 7, n. 13, p. 79-90, 2015. 
TERRA, R. N.; GOMES, C. G. Inclusão escolar: carências e desafios da formação e atuação profissional. Revista Educação Especial, Santa Maria, v. 26, n. 45, p. 109-123, 2013.

TOLEDO, E. H.; VITALIANO, C. R. Formação de professores por meio de pesquisa colaborativa com vistas à inclusão de alunos com deficiência intelectual. Revista Brasileira de Educação Especial, Marília, v. 18, n. 2, p. 319-336, 2012.

VILELA-RIBEIRO, E. B.; BENITE, A. M. C. A educação inclusiva na percepção dos professores de química. Ciência \& Educação, Bauru, v. 16, n. 3, p. 585-594, 2010.

VILELA-RIBEIRO, E. B.; BENITE, A. M. C. Alfabetização científica e educação inclusiva no discurso de professores formadores de professores de ciências. Ciência \& Educação, Bauru, v. 19, n. 3, p 781-794, 2013.

VITTA, F. C. F.; VITTA, A.; MONTEIRO, A. S. R. Percepção de professores de educação infantil sobre a inclusão da criança com deficiência. Revista Brasileira de Educação Especial, Marília, v. 16, n. 3, p. 415428, 2010.

Submetido: $15 / 01 / 2019$

Aprovado: 26/05/2020 